\title{
Strategic Determinants for Managing the Optimal Changes in the Model for Sustainable Growth
}

\author{
Prof. Dr. Ljubomir Drakulevski (Ss. Cyril and Methodius University, Macedonia) \\ Asst. Prof. Dr. Leonid Nakov (Ss. Cyril and Methodius University, Macedonia)
}

\begin{abstract}
The prior importance of the concept of sustainability, as well as its prior developmental orientation, is one of the most challenging and prospective approaches to a more systematic and a less chaotic organizational and economic growth and development. With the process of launching the "New Global Reporting Initiative", in August 2010, the awareness for a profound integration of the needed data and information on the model for sustainable growth emerged, consisting of a numerous initiative organizations, such as UN Global Compact and WWF, the Prince's Accounting for Sustainable Projects, International finance and accounting standard settlers, which in fact establish a concept of comparable integrated sustainable framework. The dominant importance of the above framework is unifying the information for running the day-to-day operation in a sustainable manner, in order to emphasize the focal understanding of the sustainability as triple bottom line aspects - the balance of harmony between the economic, social and environmental sustainability. Each organizational form nowadays possesses a need for complying its performance as a dynamic, vital and alive entity, in order to shift the prevalent consideration of the human resources from a source of value creation, to a focal creative force within, as an initial step for a vivid responding to the features of the new organizational evolution. The systemic approach to planning and implementing changes is the base for the tendencies of an external adaptation and internal integration.
\end{abstract}

\section{Creating Strategic Capability for Optimal Systems Change}

The prevalent issue for optimizing the direction and intensity of every sustainable growth, especially the organizational one, refers to the need for harmonizing the values and virtues of the sustainability with the interests of the constituencies (economic, environmental and social) and the strategic organizational determinants, especially the dimension of the strategic choice. On an organizational level, the industrial ecology, eco-efficiency and the strategic pro-activity (McDonough and Braungart, 2002) constitute the critical elements for satisfying the increasing importance of strategic determination of the scope and nature of the planned organizational changes, particularly to the optimal changes. Their integration leads to the model of dynamic coevolution towards sustainability, which is especially important in societies where accepted business practices could potentially result in a non-compliance with the social and environmental consequences of the profitable change initiatives.

The model for sustainable organizational development shifts the traditional paradigm for perceiving this process as focused only on full achievement on the mission and building and maintaining the long-term organizational capacity, which relies on the behavioral usage of the obtained knowledge and experience for the planned systemic character of the organizational processes. The focal problem of this approach is its constrained potential for managing the complex and dynamic nature of the needed balance of interests among the natural environments, the organization and its employees (Law, 2004).

In order to create and further enhance the model for managing the changes and development, the developmental issues from the so called third generation of the organizational development (Seo et al., 2004) pay particular attention to the importance of the advanced sustainable growth concepts, such as the appreciative inquiry, the learning organization, process interventions such as open space technology aimed at transformational change (Benn \& Baker, 2009). In its essence, the appreciative inquiry is affected through the action research programs, the learning organization through the throughput segment of the systemic model, whereas the process interventions predominantly refer to the business process reengineering concept.

The process of creating strategic capability for optimal systems change is initiated with the pre-conditions for an optimal changes, which is related to enabling the usage of the following key elements:

- Complex and adaptive systems thinking - CAS (Benn \& Baker, 2009);

- Collective accountability and sustainable change (Linkins et al., 2013);

- $\quad$ SIDA twinning method for organizational learning (Jones, 2001).

Complex and adaptive systems thinking - CAS in fact implies to a network of interdependent, complex and highly interactive network of change agents within and outside of the enterprise, which are mutually connected by common and shared interests, motives, goals and attitudes. The intention of their creation is to broaden the perspective for the change, from a linear, fragmented and mechanistic one, to a non-linear, integrated and organic character, in order to enable the model for a collective action for innovation, both of the enterprise and the 
society at the same time. It is only possible if the enterprise reaches its developmental phases, the moments of actual implementation of the proposed changes.

The dimension collective accountability and sustainable change is placed on the top of the pyramid of building blocks for a systems change, which is a very sensitive element in building the relationship between the enterprise and the society, from partnership to collective accountability, on the following way:

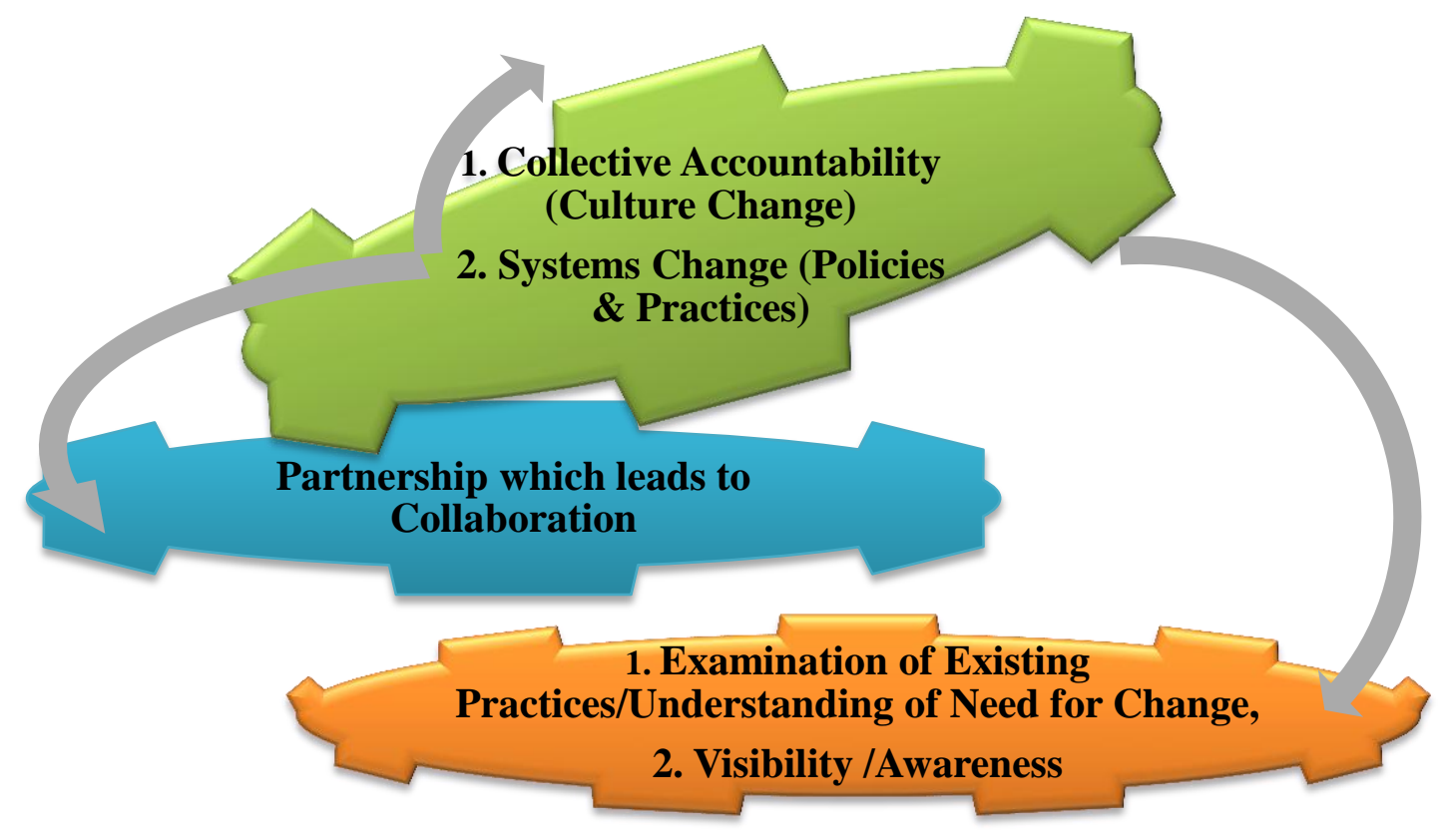

Figure 1. The Building Blocks of Systems Change Source: Adopted according to Linkins W. Karen et al.

In this element, the very collective accountability underlines a far deeper and broader internal and external commitment of every company to the process of managing the optimal changes, starting from the content understanding of the problem, through building the capacity for balancing the interests, up to the level of establishing the sustainable change, in terms of harmonizing the buy-in with the integration of the culture change with the policies and practices. The potential obstacles to collective accountability usually include lack of change champions and experience, extreme accent to the resource control, lack of accountability for quality dimensions of the outcomes, professional training and development which is not focused on the participation and collaboration, but on professional expertise, internal competition across various organizational units etc.

SIDA twinning method for organizational learning is one of the most prominent sustainable change techniques, created as a direct response to the deficiencies of the conventional technical models which rely on extensive infrastructural support along with the formal education and training of key individuals, in the relations of the developing countries, as Macedonia, with Sweden. It precisely stipulates that the key to the strategic treatment of the organizational change process lies in the integral development of the organizations, on a micro level, as well as to the institutions, on a macro level. The ultimate goal is to determine as many cooperation fields as possible and sharing each other experience and expertise.

The integration of the above detailed pre-conditions for optimal changes is effected through the principles for improving the long-term capability for change (Beer \& Eisenstat, 1996):

1. The change process should be systemic - evident need for ensuring alignment between all critical elements of the organizational design should be conducted by application of the dialectic or conflictive approach to change;

2. The change process should encourage the open discussion of barriers to effective strategy and adaptation - focuses on the necessity for an interactive understanding process of reaching a mutually acceptable understanding of the problem, in which a clear distinction of major and minor problems would enable the categorization of the change management models compared to small interventions and routine adjustments within the system;

3. The change process should develop partnership among all relevant stakeholders - collective accountability, as well as the adaptive systems thinking would not produce the desired results, if is not established a closer interaction of the enterprise with all key stakeholders. This collaboration is particularly important in times of potential various interpretations of the internal and external implications of a certain managerial actions. 
In the first principle, an effective leadership is required; in the second the usage of change agents is of a central importance, whereas in the third one, a common understanding of the indicators for the entire, not only the organizational, quality of the performance is of an utmost importance.

Strategic approaches to overcoming the barriers for collective accountability include various ranges of techniques, out of which the prevalent ones (Kramer, 2009) include the following:

- Taking responsibility for achieving results;

- Mobilize a campaign for change;

- Use all available tools and

- Create actionable knowledge.

Therefore, a mutual collective responsibility, through a detailed action change programs, with a series of available tools that are constrained by the actual resource and capability scope and nature, would lead to a new, structured and applicative knowledge.

\section{Managing the Model of Sustainable Changes and Development}

Every prosperous organization, in attempting to create and manage a model of sustainable changes and development, faces a clear need for a proper fulfillment of the following dilemmas for sustainability (Bloodgood \& Morrow, 2003):

- Specific strategic choice for their optimal changes must be comprised of the actual environmental structure, internal conscious awareness and knowledge;

- The applicative strategic choice would always reflect one of the change strategies, far more than their combination.

The compliance of the resource allocation within the selected change strategy leads to enhanced usage of the knowledge in accordance with the degree of the internal conscious awareness. As a result, the mechanisms for a more solid corporate governance, as well as the controlling process become more vital, leading to a higher overall organizational performance.

The most commonly used method for an optimal combination of the elements of the strategic choice refers to continuous knowledge transfer, transparent environmental consequences of the change action programs and a resource reconfiguration according to the features of the new organizational and social paradigm for change. The emerging of this modern paradigm is derived from the need for urging changes in the key characteristics of the management model aimed at achieving the optimal changes (Bulc, 2012), consisting of the following:

- Sustainability and sustainable development;

- Technologies;

- Innovation and

- New structures and leadership styles.

The concept of sustainability and sustainable development are best described through the following determinations, meaning that the sustainability, on one hand, is about integrating (Dyllick \& Hockerts, 2002) the following elements:

- Economical, environmental and social aspects - the triple aspects;

- Short-term and long-term aspects;

- The process of consuming the income, not the capital.

The model of sustainable development, on the other hand, incorporates the methods for achieving the following elements:

- Balancing the triple aspects for the welfare of the current and future generations (World Commission on Environmental and Development);

- Commitment to the long-term results of the responsible actions on a daily basis and the development of long-term processes in harmony with nature (Bulc, 2012);

- Sustainable work systems referred to as 'regenerative work', in terms of the resources of the employees, rather than diminishing them, development of both human and social resources (Kira \& Forslin, 2008).

The same way as human beings develop themselves in physical, emotional and mental aspects, the advancement of the enterprises must possess the holistic concept in which, the external constraints influence the re-direction of resources, with an ultimate aim of material and non-material prosperity.

The importance of applying a proper and advanced technology obviously has its internal, as well as external perspective of consequences. The fundamental issue in changing the used technology of every enterprise implies 
to the potential changes in organizational, infrastructure and administrative requirements, which in return create a more frequent orientation for an evolutionary - incremental approach for technology changes, relying on stepby-step enhancing the employee capabilities and competencies.

At the same time, actual technology of an enterprise reflects the relationship of the dominant organizational structures and systems, which is crucial for the distribution of authorities, power and influence, not only internally in the organization, but also in the processes of cooperation and support with the external stakeholders.

Changes of the technology influence the direction and character of the individual, group/team and the organizational sustained growth and development. In this context, the advancement of the technology may be far above or below the competences of the work force, or it may be vice versa. In both cases, the lack of congruency should never be an obstacle for planned technology changes, which are expected to accomplish, in our profound analyses, the following challenges:

- Integrate and optimize the development path of the technology within the prevalent organizational culture, as well as

- Determine and harmonize the technological changes with the relationship of the actual and desired level of the organizational sustainability.

With regards to the model for sustainable growth, the technology is expected to include the local, regional and national constraints to the sustainability within the processes of its ongoing development, in order to create a basis for a competitive advantage.

The third characteristic for achieving the optimal changes refers to the particular treatment, current and potential, of the innovation, analyzed both as a process and as a desired outcome. The classical approach to the innovation is concentrated on a wide range of critical-to-success stakeholders, especially to the customers, suppliers, competing innovators, regulatory bodies, media, managers and shareholders. The prevalent model of analyzing the companies' innovative tendencies relies on the cognitive approach, in terms that their perception of the influence of the innovation to the overall social and environmental development is more important than the actual innovation potential.

Innovation is in the essence of both the effectiveness and efficiency and it implies that the changes of the innovative model must me well managed. The specific character of the innovation and especially it's relation and influence to the sustainable development leads to creating a separate strategy for innovative development, in which the integration of the internal with the external demands often seem to be exhausting and resource consuming. This has been widely implemented by the trans-national companies, such as DuPont Co., which publicly announced and reduced the gas emission, by 2010, by two-thirds, while at the same time maintaining the energy usage to the 1990 levels.

The focal sustainable dimension at the innovation undoubtedly is its development potential. This innovative concept involves transparent determination of the capacity of the innovative process for an organizational transition or transformation, varying on the extensive usage of the transactional or transformational change modality. The influence of the innovation towards the sustainable growth and development is measured by the achieved, not by the perceived, changes in applicative clearing up of the obstacles, negative tendencies, withdrawals as well as to the behavioral constraints, for an intensive application of planned and continuous changes. It is in fact, an initial pre-condition for the model of sustaining the organizational growth and development.

Each and every innovation possesses various influencing potential to the sustainable innovative process. In this context, for instance, technological innovation not always bears the characteristics of an innovation for sustainable development, especially owing to non-compliance of the interests of the triple aspects model. Therefore, changes in the innovative process must be driven and conducted in accordance with the organizational goals of the optimal changes, and at the same time with the major causes of social and environmental disruptions.

The innovation itself, adds value not only to the processes, but also to the internal and external relations across the company and along with the environment. It is of a fundamental importance to emphasize that primary initiative for measuring the sustainability have been developed within the Global Reporting Initiative $(G R I)$, where the mail goal is to determine the link between the sustainability and the economic value of the enterprise, especially whether it is present in everyday managerial actions. In other words, the cost of the capital, analyzed as an investment from the entire financial community in the corporation, must be surpassed by the output of using the capital resources.

The concept of Economic Value Added (EVA) (Bardy\& Massaro, 2012) stipulate that it is possible to measure the overall corporate performance by claiming that shareholders gain when the return from the capital employed in a corporation is greater than the cost of the same capital. It's advantage lies in the fact that it is possible to measure and implement the sustainability at site levels, industry level, division level, regional level and national level, whereas sustainable development is mainly a macro-level concept at the global level (Jasch, 2006). 
The integrative usage of the ecological and social resources, predominantly through the degree of their nominal and real availability, leads to finding out the corporate contribution to sustainability, in terms that it is expected to use them on a more efficient level, if they pledge to be treated as a sustainable capital, as a monetary indicator of the sustainability.

The ultimate indicator from the models of adding value tends to be the concept of Sustainable Value Added (SVA), which is calculated when we take the Economic Value Added (EVA) and deduct the cost of capital employed in ecological resources and the cost of capital employed in social resources. In a word, it is the net economic outcome from the invested capital in the sustainability.

Both above detailed value based sustainability approaches are widely applied in numerous countries of the European Union, such as in Denmark, Sweden etc. The achieved results confirm the prior assumptions than the model of sustainable growth does not only waste value, but adds value, especially in the managerial actions where the interests of preserving and developing the environment, and the treatment, training and performance enhancement of the employees is high on the managerial operating agenda.

Inevitably, innovation is the key characteristic for achieving optimal change, in which the transformational potential creates the added value, within the prevalent model of awareness and consciousness, and the efficient allocation of the available resources. Therefore, the adoption of the innovation is dependent by various factors, among which the shareholders complexity, the shareholders ambiguity and the sustainable development pressure (Hall \& Vredenburg, 2013) plays the highest importance.

In order to determine the potential of the innovation towards the optimal change within the model of sustainable growth, the focal dimension is to analyze the counter relationship between their stimulating forces, on one hand, and their orientation towards the competitive recognition, on the other hand. With regards to the stimulating forces, the distinction is on:

- Market-driven innovation and

- Public-policy driven innovation.

The competitive recognition varies from the modalities of influencing the following competitive dimensions:

- Competitive advantage or

- Competitive disruption.

Their integration is analyzed on the following way:

\begin{tabular}{|c|c|c|}
\hline & $\begin{array}{l}\text { Market-Driven } \\
\text { Innovation Stimulus }\end{array}$ & $\begin{array}{l}\text { Public-Policy-Driven } \\
\text { Innovation Stimulus }\end{array}$ \\
\hline $\begin{array}{l}\text { Opportunity for } \\
\text { Competitive } \\
\text { Advantage }\end{array}$ & $\begin{array}{l}\text { EXPLOIT CUSTOMER NEED - } \\
\text { New or improved products/services }\end{array}$ & $\begin{array}{l}\text { EXPLOIT SOCIETAL NEEDS - } \\
\text { Wealth creation, Energy security, } \\
\text { National and Regional Economic } \\
\text { development or Environmental } \\
\text { protection }\end{array}$ \\
\hline $\begin{array}{l}\text { Opportunity for } \\
\text { Competitive } \\
\text { Disruption }\end{array}$ & $\begin{array}{l}\text { RISK OF FAILURE AND } \\
\text { OBSOLESCENCE - } \\
\text { Uncompetitive technology or } \\
\text { Business practice }\end{array}$ & $\begin{array}{l}\text { RISK OF SOCIETAL TURMOIL - } \\
\text { Environmental degradation or Social } \\
\text { inequalities }\end{array}$ \\
\hline
\end{tabular}

Table 1.The Double-Edged Sword of Innovation Source: Hall Jeremy \& Harry Vredenburg

In order to satisfy at the same time the needs of the organization, employees and the environment, management should concentrate on both, left and right side of the detailed Table 1.1., especially owing to the fact that business executives traditionally focus on the left side, whereas the policy-makers on the rights side of it. The key for a more thorough and integrating application of the above Table lies in the prevailing concept of the development of the skills and competencies of all the employees, including the managers, meaning that the enterprise has a need for internally and externally unifying the sources of competitiveness with the fundamental interests of all key stakeholders for the sustainable development.

The final characteristic of the managerial model for achieving optimal changes are the new structures and leadership style. The tendency of every open organizational system should be placed in adjusting the changes within all structures, not only in the organizational scheme, to the existing and future needs of all interest parties from the enterprise.

Therefore, the structural changes are expected to reflect the changes which are required for sustained concept of managing the optimal changes, a fact that in return constitutes the need for an anticipative determination of the scope and the direction of those changes for more flexible and adaptive structures. At the same time, the model of leadership style defines the character of the relations of the leaders towards their followers, a moment which should add stimulus and new energy at all employees, particularly to integrating the previous 3 
characteristics for achieving the optimal change. The leadership changes must be focused on the development of the concept leadership within, which enables the enterprise to function as a dynamic and agile system, with a prior focus on constant sustainable changes for the desired level of transition or transformation, through collective, not individual consciousness and awareness.

The key for the changes for new structures and leadership style is placed in the concept of transition from learning to a thinking environment, what underlines the fact that contemporary managers are not expected to manage only the source of creating the value, but also the generating segment of the value creation, i.e. the environment.

In essence, an organization, while attempting to reach an optimal change for a sustainable growth, should create a continuous change program, not an episodic, or an incidental one. In this program, managers are about to implement the concept of stakeholders interest balance (Beer \& Nohria, 2000), through the priorities of the created model for sustainable development, internal and external. In this matter, it is essential to distinct the following sustainable pathways points:

- Clear differentiation of the strategy for creating - predominantly bottom up, to the strategy for maintaining or sustaining the change - predominantly top down (Meyer \& Stensaker, 2006);

- In the implementation stage of managing the optimal change, a discrete change should come first, and followed by a continuous changes (Buchanan et al., 2005);

- The optimal character of the change lies in the sustainability of the continuous change programs, which is determined by the following enablers for long-term effect of the optimal change (Swensson, 2007):
- Managerial ownership to the change initiative;
- Professional steering of the change process;
- Competent leadership; and
- Engaged participants.

The integration of above enablers enacts actual measurement of the sustainability of the optimal changes and positively influence to the competitive advantage of the enterprise.

\section{Conclusion}

The prior importance of the concept of sustainability in the contemporary economy and society as a whole, as well as it's prior orientation in the function of creating a model for managing an optimal changes and growth is one of the most challenging and prospective approaches to a thorough and consistent necessity for a more systematic and a less chaotic organizational and economic growth and development.

The prevalent issue for optimizing the direction and intensity of every sustainable growth, especially the organizational one, refers to the need for harmonizing the values and virtues of the sustainability with the interests of the constituencies (economic, environmental and social) and the strategic organizational determinants, especially the dimension of the strategic choice.

The process of creating strategic capability for optimal systems change is initiated with the pre-conditions for an optimal changes, which is related to enabling the usage of the following key elements - complex and adaptive systems thinking - CAS, collective accountability and sustainable change and SIDA twinning method for organizational learning. The potential obstacles to collective accountability usually include lack of change champions and experience, extreme accent to the resource control, lack of accountability for quality dimensions of the outcomes, professional training and development which is not focused on the participation and collaboration, but on professional expertise, internal competition across various organizational units etc.

The emerging of the modern paradigm of strategic choice is derived from the need for urging changes in the key characteristics of the management model aimed at achieving the optimal changes, consisting of the sustainability and sustainable development, technologies, innovation and new structures and leadership styles. The innovation itself, adds value not only to the processes, but also to the internal and external relations across the company and along with the environment. It is of a fundamental importance to emphasize that primary initiative for measuring the sustainability have been developed within the Global Reporting Initiative (GRI), where the mail goal is to determine the link between the sustainability and the economic value of the enterprise, especially whether it is present in everyday managerial actions. In other words, the cost of the capital, analyzed as an investment from the entire financial community in the corporation, must be surpassed by the output of using the capital resources.

The optimal character of the change lies in the sustainability of the continuous change programs, which is determined by the following enablers for long-term effect of the optimal change - managerial ownership to the change initiative, professional steering of the change process, competent leadership and engaged participants. 


\section{References}

- Bardy Roland \& Maurizio Massaro, 2012, “A stimulus for sustainable growth and development: Construing a composite index to measure overall corporate performance", Journal of Organizational Transformation and Social Change, Vol.9, No.2, p.160

- Benn Suzanne \& Ellen Baker, 2009, “Advancing Sustainability Through Change and Innovation: A Coevolutionary Perspective", Journal of Change Management, December, Vol.9, No.4, p.386

- Bloodgood M. James \& J.L. Morrow Jr., 2003, "Strategic Organizational Change, Exploring the Roles of Environmental Structures, Internal Conscious Awareness and Knowledge”, Journal of Management Studies, November, Vol.40, No.7, p.1771

- Brannmark Mikael \& Suzanne Benn, 2012, “A Proposed Model for Evauating the Sustainability of Continuous Change Programmes”, Journal of Change Management, June, Vol.12, No.2, p.235

- Bulc Violeta, 2012, "New Organizational and social paradigm: From cooperation to co-cretaion and sustainable coexistence", Journal of Organizational Transformation and Social Change, Vol.9, No.1, p.37

- Fukukawa Kyoko, David Spicer, Sally Ann Burrows and Jenny Fairbrass, 2013, "Sustainable Change Education for Sustainable Development in the Business School", Journal of Corporate Citizenship, March, Vol. 49, p.78

- Hall Jeremy \& Harry Vredenburg, 2003, “The Challenges of Innovating for Sustainable Development”, MIT Sloan Management Review, Fall, p.64

- Jones L. Merick, 2001, "Sustainable organizational capacity building: Is organizational learning a key?", International Journal of Human Resource Management, February, Vol.12, No.1, p.94

- Kumar Sameer, Wendell Spence and Philip Swartzer, 2012, "Lessons from strategic organizational growth performance challenges for US automakers", Human Systems Management, Vol.31, p.206

- Linkins W. Karen et al., 2013, "Moving from Partnership to Collective Accountability and Sustainable Change: Applying a Systems-Change Models to Foundations' Evolving Roles”, Foundation Review, Vol. 5, No.2, p.53

- Purkayastha Debapratim, 2012, “MCX’s 'Gramin Suvidha Kendra'; A Sustainable Model for Inclusive Growth”, Journal of Business Strategy, p.50 